\title{
TÁC ĐỘNG TRÁCH NHIỆM XÃ HộI CỦA DOANH NGHIỆP ĐẾN HÀNH VI MUA CỦA KHÁCH HÀNG TẠI THÀNH PHỐ HỒ CHÍ MINH
}

\author{
NGUYỄN THI VÂN \\ Khoa Quản trị kinh doanh, Trưòng Đại học Công nghiệp thành phố Hồ Chi Minh \\ nguyenthivan@iuh.edu.vn
}

\begin{abstract}
Khách hàng là một trong những nhân tố quan trọng quyết định sự thành bại của $\mathrm{DN}$, và hiện nay khi đưa ra bất kỳ một quyết định mua sắm nào, ít nhiều họ đều quan tâm xem $\mathrm{DN}$ có thực hiện tốt trách nhiệm xã hội hay không. Nghiên cứu này được thực hiện nhằm phân tích sự tác động chính sách trách nhiệm xã hội của doanh nghiệp đến hành vi mua của khách hàng tại thành phố Hồ Chí Minh từ đó xác định các nhân tố ảnh hưởng và trọng số của từng nhân tố, dùng làm cơ sở để nhóm tác giả đưa ra các hàm ý quản trị nhằm nâng cao hiệu quả kinh doanh cho doanh nghiệp tại TPHCM. Sử dụng phương pháp nghiên cứu định tính và định lượng, nhóm tác giả tiến hành khảo sát 274 người với 27 biến quan sát. Kêt quả nghiên cứu cho thấy có 05 nhân tố tác động như sau: trách nhiệm về kinh tế, trách nhiệm về pháp luật, trách nhiệm về đạo đức, trách nhiệm về từ thiện, và trách nhiệm về môi trường tác động tích cực đến hành vi mua của khách hàng tại thành phố Hồ Chí Minh.
\end{abstract}

Từ khóa: Trách nhiệm xã hội doanh nghiệp, hành vi mua của khách hàng, doanh nghiệp, thành phố Hồ Chí Minh.

\section{THE INFLUENCE OF CORPORATE SOCIAL RESPONSIBILITY POLICIES ON BUYING BEHAVIOR OF CUSTOMERS IN HO CHI MINH CITY}

\begin{abstract}
Customers are one of the important factors determining the success or failure of businesses, and nowadays when making any purchase decision, they are more or less interested in enterprises' social responsibility. This research was conducted to analyze the influence of Corporate Social Responsibility (CSR) policies on buying behavior of customers in Ho Chi Minh City and identify influencing factors as well as their weights. The results are used for suggesting solutions to improve enterprises' performance in Ho Chi Minh City. The qualitative and quantitative research methods were used to survey 274 people with 27 observed variables in order to determine factors affecting Buying behavior of customers in Ho Chi Minh City. The results showed that there are five factors: economic responsibility, legal responsibility, ethical responsibility, responsibility for charity, and environmental responsibility influence buying behavior of customers in Ho Chi Minh City.
\end{abstract}

Keywords: Corporate Social Responsibility, Buying behavior of customers, Enterprise, Ho Chi Minh City.

\section{GIỚI THIÊU}

Khách hàng chính là người mua và sử dụng hàng hóa, dịch vụ do các doanh nghiệp $(\mathrm{DN})$ cung cấp, đây là một trong những nhân tố quan trọng quyết định sự thành bại của doanh nghiệp. Khi đưa bất kỳ một quyết định mua sắm nào, khách hàng có quyền được tự do tham khảo, chọn lựa sản phẩm mình muốn mua và sử dụng theo đúng nhu cầu và mục đích của mình. Chính từ nhu cầu mua sắm, doanh nghiệp sẽ lên kế hoạch đưa ra nhiều sản phẩm, dịch vụ đa dạng nhằm đáp ứng nhu cầu sử dụng ngày càng cao của khách hàng, đồng thời tăng tính cạnh tranh giữa các doanh nghiệp. Cùng với đó, khách hàng có thể đưa ra những ý kiển đóng góp hữu ích và chính xác về sản phẩm và dịch vụ mà mình sử dụng. Tùy thuộc vào thị hiếu và ý kiến thu thập được từ phía khách hàng, người tiêu dùng, doanh nghiệp có thể điều chỉnh lại phương pháp sản xuất, hoàn thiện sản phẩm cho phù hợp với nhu cầu của họ. Chính lẽ đó, khách hàng có vai trò quan trọng trong việc thúc đẩy các doanh nghiệp thực hiện trách nhiệm xã hội (TNXH).

Trên thế giới có những doanh nghiệp vi phạm pháp luật có thể gánh hậu quả nghiêm trọng khi người tiêu dùng, đối tác tẩy chay sản phẩm. Câu chuyện Hãng điện tử Samsung vào tháng 7-2014 đã thông báo việc tạm đình chỉ kinh doanh với một nhà cung cấp ở Trung Quốc khi hãng này có bằng chứng về việc nhà cung cấp sử dụng lao động trẻ em bất hợp pháp. Hay câu chuyện các nhà hoạt động nhân quyền và quan chức 
Mỹ vào tháng 12-2015 đã từng kêu gọi người Mỹ ngưng mua tôm có nguồn gốc từ Thái Lan sau khi một phóng sự điều tra của một hãng thông tấn lớn phát đi cho thấy tình trạng bóc lột người lao động như nô lệ trong ngành tôm của Thái Lan.

Cùng với quá trình toàn cầu hóa, người tiêu dùng Việt đã dần ý thức được quyền "tẩy chay" của mình đối với những sản phẩm của doanh nghiệp gây ảnh hưởng tới sức khỏe, môi trường và lợi ích xã hội qua hành động mua sắm và thiết lập quyền kiểm soát rộng khắp của họ đối với việc sản xuất. Thực tế hiện nay, người tiêu dùng không chỉ quan tâm đến chất lượng sản phẩm mà còn coi trọng cách thức các công ty sản xuất sản phẩm đó như thế nào, hàng hóa đó có thân thiện với môi trường, cộng đồng, doanh nghiệp tuân thủ pháp luật, cách hành xử trong kinh doanh có đạo đức và lành mạnh hay không... ví dụ như giữa năm 2010, hàng loạt siêu thị, chợ và người tiêu dùng đã đồng loạt tẩy chay các sản phẩm của Công ty Vedan, lý do là gây ô nhiễm môi trường nghiêm trọng và hàng loạt nông dân bị vỡ nợ do sự ô nhiễm gây ra, hay Công ty Tân Hiệp Phát đã bị nhiều người tiêu dùng "ngoảnh mặt" khi được cho là đã "gài bẫy" người tiêu dùng vì anh này đã yêu cầu hãng bồi thường cho việc anh mua phải chai nước có dị vật mất vệ sinh...

Các nghiên cứu về TNXH tại Việt Nam chỉ xuất hiện khoảng 20 năm trở lại đây và tập trung vào khía cạnh đạo đức và từ thiện thay vì cả bốn khía cạnh theo lý thuyết Carroll et al. (1991) [1]. Các nghiên cứu về trách nhiệm xã hội chưa làm rõ việc thực hiện TNXH theo ngành nghề mặc dù các tác giả trên đều nhận định tầm quan trọng và xu hướng phải thực thi các hoạt động CSR. Hơn nữa, các nghiên cứu lý luận và thực nghiệm trong nước đã bám sát với tình hình thực tế Việt Nam, dựa trên cơ sở lý thuyết của các nghiên cứu nước ngoài, vẫn chưa phân tích theo đặc điểm của từng ngành, phạm vi nghiên cứu hạn chế và thiếu cơ sở khoa học để đề xuất giải pháp hợp lý. Các nghiên cứu về TNXH DN tại Việt Nam vẫn còn khá khiêm tốn. Trên khía cạnh nghiên cứu mối quan hệ TNXH DN và nhận thức của người tiêu dùng đã có nghiên cứu của nhóm tác giả Nguyễn Thị Hồng Hà và Nguyễn Thị Tuyết Mai (2013) [2]. Đây là một nghiên cứu định tính trong ngành thức ăn chăn nuôi tại miền Bắc Việt Nam; Nguyễn Phan Thanh Nhã và Lê Thị Thanh Xuân (2014) [3] nghiên cứu nhận thức của người tiêu dùng về trách nhiệm xã hội của doanh nghiệp và ý định mua, nghiên cứu này liển quan ngành điện máy; Nguyễn Thị Kim Ánh và̀ Nguyễn Thị Minh Hòa (2018) [4] nghiên cứu về cảm nhận trách nhiệm xã hội đến niềm tin thương hiệu, trường hợp dịch vụ vận tải hành khách. Mặc dù vậy, Việt Nam đã đạt được một số kết quả tích cực trong củng cố nhận thức cho khách hàng, hoàn chỉnh cơ sở pháp lý và triển khai thực hiện các chủ trương chính sách, pháp luật của nhà nước trong việc bảo vệ quyền của khách hàng, cả về tuyên truyền, phổ biến pháp luật; kiểm soát hợp đồng theo mẫu, điều kiện giao dịch chung và giải quyết khiếu nại của người tiêu dùng.

Trong bối cảnh hiện nay còn rất ít các nghiên cứu định lượng về TNXH DN ở Việt Nam, đặc biệt là các nghiên cứu trong lĩnh vực tác động của TNXH đến hành vi mua khách hàng - một lĩnh vực tác động đến một số lượng người tiêu dùng rất lớn, một nghiên cứu về tác động của TNXH DN đến sự trung thành của người tiêu dùng là một nhu cầu tất yếu để các doanh nghiệp có chiến lược nhằm nâng cao hiệu quả kinh doanh. Trong khuôn khổ bài viết này tác giả sẽ tập trung nghiên cứu vấn đề "Tác động trách nhiệm xã hội của doanh nghiệp đến hành vi mua của khách hàng tại Thành Phố Hồ Chí Minh”.

\section{CƠ SỞ LÝ THUYÊT VÀ MÔ HÌNH NGHIÊN CÚU}

\subsection{Sự ra đời của thuật ngữ trách nhiệm xã hội (Corporate Social Responsibility- CSR)}

Khái niệm trách nhiệm xã hội của doanh nghiệp (Corporate Social Responsibility) trong lịch sử hình thành, và phổ biến vào những năm 50 của thế kỷ $X X$. Tuy nhiên, thuật ngữ này đã manh nha sớm hơn, cụ thể nó đã được đề cập vào những năm 1930 - 1940, trong các tác phẩm của Chester Barnard 1938 [5]"Chức năng của điều hành" (The Functions of the Executive), J. M. Clark’s 1939 "Kiểm soát xã hội của các doanh nghiệp" (Social Control of Business) [6], và Theodore Kreps's 1940 "Đo lường hiệu quả xã hội của các doanh nghiệp" (Measurement of the Social Performance of Business) [7], các tác phẩm đã đề cập đến một số mặt vấn đề TNXHDN. Tuy nhiên, giai đoạn này nội hàm còn hạn chế và chưa phải là chủ đề được nhiều người quan tâm. Sang những năm 1950 nền kinh tế phát triển mạh, sự tích lũy tư bản đã hình thành những tập đoàn, tồng công ty có quy mô lớn. Tính chất của nền sản xuất kinh doanh hiện đại, với việc sử dụng lao động theo kiểu dây chuyền của mô hình Fredericl Winslow Taylor và Henry Ford trong quản trị doanh nghiệp và đặc biệt là sự tiêu ngốn một lượng tài nguyên khổng lồ cùng với việc phát thải lượng phế thải cũng tương tự là nguyên nhân của những mối hiểm họa hủy hoại sinh quyển, sự gia tăng tình trạng bất bình đẳng đe dọa kết cẩu xã hội, tổn hại đến sức khỏe cộng đồng... Mặt khác, chính sự phản ứng của các hội đoàn, tổ chức phi chính phủ, của xã hội dân sự nói chung, đã tạo nên trào lưu xã hội gây áp lực khiến các 
doanh nghiệp - đặc biệt là các tập đoàn, các công ty đa quốc gia phải có hành động thể hiện trách nhiệm của mình với xã hội. Trước thực tiễn đó đòi hỏi cần phải có những cách thức giải thích mới về TNXHDN, và năm 1953 Howard R. Bowen (1908-1989) [8] công bố quyển sách mang tính bước ngoặt: Social Responsibilities of the Businessman - Trách nhiệm xã hội của doanh nhân. Nội dung là nhằm tuyên truyền và kêu gọi người quản lý tài sản không làm tổn hại đến các quyền và lợi ích của người khác, kêu gọi lòng từ thiện nhằm bồi hoàn những thiệt hại mà các doanh nghiệp gây ra cho xã hội.

Theo Petkus và Woodruff xác định TNXH là "tránh gây hại và thực hiện tốt nghĩa vụ kinh doanh". Mohr và các cộng sự (2001) [9] đã xác định TNXH như "cam kết công ty giảm thiểu hoặc loại bỏ bất kỳ tác động có hại và tối đa hóa tác động có lợi đối với xã hội”. Khái quát hơn Ogrized (2002) [10] cho rằng phạm vi TNXH là rộng lớn hơn nhiều so với các hoạt động từ thiện, nó bao gồm sự tham gia đóng góp cộng đồng, hệ thống quản lý môi trường và chính sách nguồn nhân lực.

Theo Dahlsrud 2008, [11] trong nghiên cứu của mình đã xác định và phân tích 37 định nghĩa khác nhau về TNXH DN. Nội dung khái niệm TNXH DN có thể đi từ quan điểm kinh tế rất hẹp, xem TNXH DN là việc tối đa hóa lợi nhuận cho các cổ đông (Zenisek, 1979) [12] cho đến một quan điểm xã hội rộng rãi xem TNXH DN bao gồm các hoạt động của công ty tôn trọng các nghĩa vụ của DN đối với xã hội hoặc ít nhất là nghĩa vụ đối với các bên liên quan (Brown and Dacin, 1997) [13]. Ngày nay CSR đã trở nên phổ biến, mặc dù có nhiều quan điểm khác nhau về khái niệm, nội dung và phạm vi của CSR. Trong số đó, lý thuyết TNXH DN theo mô hình Kim tự tháp của Carroll et al. (1991) [1] được đánh giá là mô hình đầu tiên chỉ ra cách thức để DN thực hiện TNXH của mình, mô hình Kim tự tháp được xây dựng trên bốn yếu tố: Kinh tế, Pháp lý; Đạo đức; Thiện nguyện là mô hình có giá trị, có tính toàn diện và được sử dụng rộng rãi nhất.

\subsection{Các nghiên cứu tác động của TNXH lên đối tượng khách hàng}

Các nghiên cứu về trách nhiệm xã hội của doanh nghiệp trên thế giới rẩt phong phú về chất lượng cũng như số lượng. Hai thập kỷ vừa qua, chủ đề này luôn thu hút sự quan tâm của các nhà quản lý doanh nghiệp cũng như giới học thuật, tuy nhiên phạm vi của các nghiên cứu của nó thì rộng, đa chiều (Malik, 2015) [14] và có một số chủ đề nổi bật như sau: Tác động của TNXH lên đối tượng khách hàng đa số các bài nghiên cứu trực tiếp thảo luận về tác động của TNXH lên các khía cạnh của tổ chức ở nhiều giác độ khác nhau. Đối tượng khách hàng được đề cập nhiều nhất và kết quả là các nghiên cứu chứng minh rằng nó giúp cải thiện hành vi mua (Becker-Olsenet al., 2006; McDonald và Hung Lai, 2011) [15], thu được nhiều lợi ích từ khách hàng hơn trong ngắn hạn cũng như dài hạn (Lee et al., 2012) [16], các chiến lược TNXH hướng tới khách hàng đang đi đúng hướng (Pérez và del Bosque $(2014,2015)$ [17] [18]. Tiếp theo chủ đề này là nghiên cứu tác động của TNXH lên khách hàng thông qua biến trung gian giúp gia tăng lòng trung thành của khách hàng, tăng doanh số bán (Fatma và Rahman, 2016; Karaosmanoglu et al., 2016) [19]. Hơn nữa, cuộc điều tra của MORI (2000) [20] về khách hàng, cho thấy $70 \%$ khách hàng quan tâm đến danh tiếng về đạo đức của công ty khi mua sản phẩm dịch vụ. Ngược lại, một số nghiên cứu cho kết quả không có mối liên hệ giữa các hoạt động TNXH và hành vi khách hàng (Carvalho et al., 2010; Polychronidouet al., 2014) [21] [22]. Nhìn chung, mặc dù có nhiều ý kiến tranh luận nhưng đa số các kết quả nghiên cứu khẳng định khách hàng là mối quan tâm hàng đầu của bất kỳ tổ chức kinh doanh nào, nên các hoạt động TNXH phải xây dựng trên quan điểm cảm nhận khách hàng, vì nó dẫn tới hành vi tiêu thụ các sản phẩm dịch vụ của công ty.

\subsection{Mối liên hệ giữa trách nhiệm xã hội với hành vi mua của khách hàng}

Theo Pomering và Dolnicar (2008) [23], các cuộc thăm dò đã cho thấy người tiêu dùng mong muốn các doanh nghiệp cung cấp thông tin về những gì họ làm và người tiêu dùng sẽ hổ trợ lại cho các doanh nghiệp nào đang theo đuổi các hoạt động TNXH. Environics (1999)[24] tiến hành cuộc khảo sát liên quan đến phản ứng của người tiêu dùng đối với CSR. Kết quả cho thấy người tiêu dùng Úc có trách nhiệm xã hội cao nhất.

Tay K. L. [25] kết luận rằng, khi xã hội trở nên giàu có hơn thì việc đối mặt với nhận thức người tiêu dùng cao hơn, họ trở nên nhạy cảm hơn với cách thức mà doanh nghiệp cư xử, do đó có thể ảnh hưởng đến hành vi mua sắm sản phẩm và sử dung dịch vụ của họ.

Nghiên cứu của Rahizah Abd Rahim và cộng sự (2011) [26] tại thị trường Malaysia nhằm xem xét ảnh hưởng của TNXH đến hành vi mua của người tiêu dùng Malaysia. Với mẫu khảo sát chọn ngẫu nhiên 220 người dân sống trong 5 tiểu bang của Malaysia bao gồm: Johor, Perak, Selangor, Sabar và Sarawak. Kết quả mối quan hệ dương giữa các biến đo lường của TNXH bao gồm: kinh tế, pháp lý, đạo đức và từ thiện 
với hành vi mua của người tiêu dùng trong đó TNXH về kinh tế tác động mạnh nhất, kế đến là TNXH về từ thiện, tiếp theo là đạo đức và pháp lý.

\section{Mô hình nghiên cứu}

Căn cứ vào các kết quả nghiên cứu khoa học của các tác giả như (H.R.Bowen, 1953, Archie. B Carroll, 1979; Jimmy \& L.A, 2012) học thuyết marketing quan hệ của David Lam (2012) học thuyết marketing 2.0 của Philip Kotler (2010)[27] và nhiều kết quả nghiên cứu khoa học liên quan như nêu trên, tác giả tham khảo ý kiến của các chuyên gia để xây dựng mô hình nghiên cứu và tiến hành nghiên cứu sơ bộ trước khi đề xuất một mô hình nghiên cứu chính thức như sau:

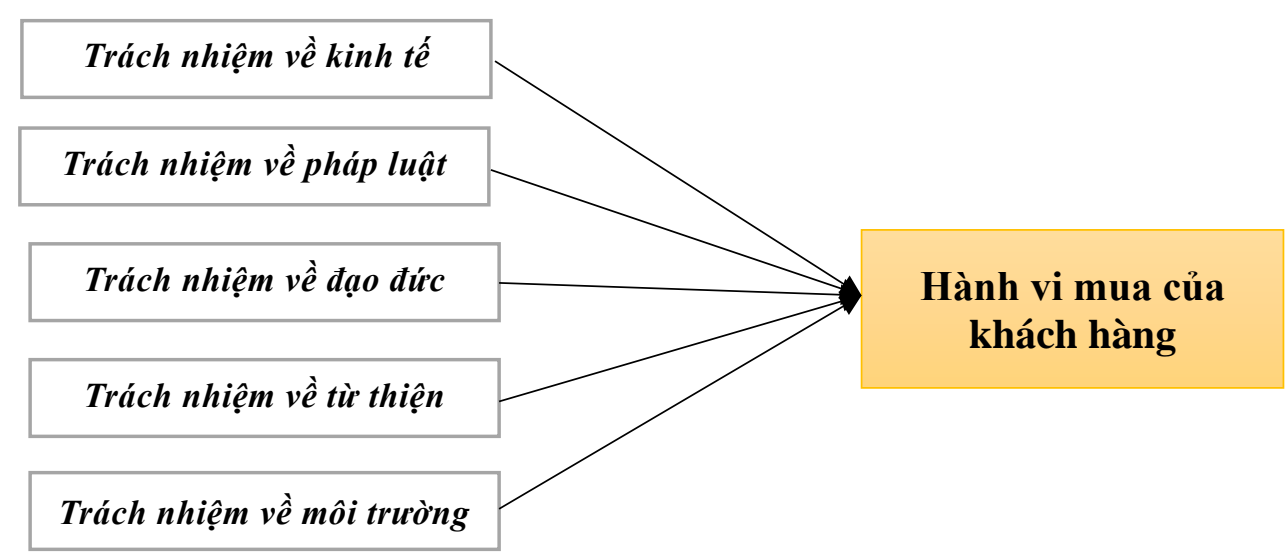

\section{Các giải thuyết cho nghiên cứu:}

Figure 1: Mô hình nghiên cứu

H1: "Trách nhiệm về kinh tế" có tác động đến hành vi mua của khách hàng tại TPHCM

H2: "Trách nhiệm về pháp luật" có tác động đến hành vi mua của khách hàng tại TPHCM

H3: "Trách nhiệm về đạo đức" có tác động đến hành vi mua của khách hàng tại TPHCM

H4: "Trách nhiệm về từ thiện" có tác động đến hành vi mua của khách hàng tại TPHCM

H5: "Trách nhiệm về môi trường" có tác động đến hành vi mua của khách hàng tại TPHCM

\section{PHƯƠNG PHÁP VÀ KẾT QUẢ NGHIÊN CÚU}

Nghiên cứu được thực hiện thông qua các giai đoạn:

Giai đoạn 1: thiết kế bảng câu hỏi và tiển hành khảo sát (sau khi khảo sát sơ bộ, tìm hiểu cơ sở lý thuyết và xây dựng mô hình nghiên cứu)

- Sử dụng thang đo Liker 5 mức độ, để đo lường hành vi mua của khách hàng tại TPHCM với các nhân tố mô hình ban đầu.

- Mẫu nghiên cứu: có 300 bảng câu hỏi được phát ra, thu về 285 bảng câu hỏi được phản hồi, sau khi loại đi các phiếu trả lời không đạt yêu cầu, còn lại 274 phiếu. Như vậy cơ sở dữ liệu đưa vào và xử lý dữ liệu và phân tích là 274 mẫu nghiên cứu (đạt tỷ lệ 91, 3\%)

Giai đoạn 2: xử lý số liệu và thống kê kết quả

Nghiên cứu sử dụng phương pháp định lượng, tiến hành đánh giá độ tin cậy của thang đo bằng hệ số Cronbach alpha, phân tích nhân tố khám phá (EFA), theo Trọng H. và Ngọc N. M. C. [28], những quy tắc kinh nghiệm trong xác định cỡ mẫu cho phân tích nhân tố là số quan sát (kích thước mẫu) ít nhất phải bằng 4 hay 5 lần số biển trong phân tích nhân tố. Đối với phân tích nhân tố khám phá (EFA), dựa theo nghiên cứu của Hair và ctg (1998) [29] để có thể phân tích phân tích nhân tố khám phá (EFA) cần thu thập bộ dữ liệu với ít nhất 5 mẫu trên 1 biến quan sát $(27 \times 5=135$ mẫu). Mẫu được chọn theo phương pháp chọn mẫu thuận tiện theo điều kiện gạn lọc những khách hàng có kiến thức về kinh tế, hiểu biết về chính sách xã hội của doanh nghiệp tại TPHCM.

Kết quả nghiên cúu 


\subsection{Thống kế mô tả}

\begin{tabular}{|l|l|c|c|}
\hline \multicolumn{4}{|c|}{ Bảng 1. Mô tả mẫu đghiên cứu } \\
\hline \multirow{2}{*}{ Giới tính } & Nam & Tần suất & Phần trăm (\%) \\
\cline { 2 - 4 } & Nữ & 172 & 62.8 \\
\hline \multirow{3}{*}{ Độ tuổi } & Dưới 18 & 102 & 37.2 \\
\cline { 2 - 4 } & $18-30$ & 0 & 0 \\
\cline { 2 - 4 } & $30-45$ & 242 & 88.3 \\
\cline { 2 - 4 } & $45-60$ & 18 & 8.8 \\
\hline \multirow{5}{*}{ Trình độ học vấn } & Trung học & 14 & 2.9 \\
\cline { 2 - 4 } & Cao đẳng & 12 & 2.5 \\
\cline { 2 - 4 } & Dại học & 212 & 4.3 \\
\cline { 2 - 4 } & Trên đại học & 43 & 77.3 \\
\hline \multirow{5}{*}{ Thu nhập } & Dưới 5 triệu & 25 & 15.9 \\
\cline { 2 - 4 } & Từ 5 - 15 triệu & 120 & 9.1 \\
\cline { 2 - 4 } & Trên 15 triệu & 129 & 43.7 \\
\hline
\end{tabular}

Kết quả thống kê cho thấy tỉ lệ giới tính, độ tuổi, trình độ học vấn của những người được khảo sát có sự chênh lệch. Trong đó độ tuổi được tập trung vào khoảng từ 18 - 45 vì đây là độ tuổi có kinh nghiệm và thu nhập và những kiến thức nhất định về sản phẩm và dịch vụ của doanh nghiệp.

Bảng 2. Kiểm định giá trị trung bình cho các biến quan sát

\begin{tabular}{|c|c|c|}
\hline Biến quan sát & $\mathbf{N}$ & $\begin{array}{l}\text { Trung } \\
\text { bình }\end{array}$ \\
\hline Doanh nghiệp luôn cải thiện hiệu quả kinh doanh & 274 & 3.36 \\
\hline Mục tiêu của Doanh nghiệp là duy trì lợi thế cạnh tranh & 274 & 3.33 \\
\hline Doanh nghiệp phấn đấu đạt lợi nhuận cao nhất cho các cổ đông của mình & 274 & 3.34 \\
\hline Doanh nghiệp cố gắng giảm chi phí hoạt động của DN & 274 & 3.48 \\
\hline Doanh nghiệp cung cấp hàng hóa và dịch vụ với giá cả hợp lý & 274 & 3.34 \\
\hline Doanh nghiệp có nhận thức về pháp luật tốt & 274 & 3.40 \\
\hline $\begin{array}{l}\text { Doanh nghiệp khuyến khích nhân viên của mình làm việc theo đúng quy định của } \\
\text { pháp luật }\end{array}$ & 274 & 3.57 \\
\hline Doanh nghiệp có nhiều hoạt động phổ biến, tuyên truyền pháp luật tốt & 274 & 3.43 \\
\hline Doanh nghiệp cung cấp đúng hàng hóa và dịch vụ như đã cam kết & 274 & 3.35 \\
\hline Doanh nghiệp thực hiện đúng nghĩa vụ hợp đồng giữa các bên đã ký & 274 & 3.13 \\
\hline Doanh nghiệp có chất lượng sản phẩm/ dịch vụ tốt & 274 & 3.20 \\
\hline Doanh nghiệp cung cấp thông tin trung thực trong các chương trình quảng cáo & 274 & 3.04 \\
\hline $\begin{array}{l}\text { Doanh nghiệp này coi trọng các giá trị đạo đức trong kinh doanh hơn những lợi ích } \\
\text { nhất thời khi giải quết sự cố phàn nàn từ phía khách hàng }\end{array}$ & 274 & 3.13 \\
\hline Doanh nghiệp này có môi trường làm việc tốt cho người lao động & 274 & 3.18 \\
\hline Doanh nghiệp đối xử với khách hàng công bằng & 274 & 3.18 \\
\hline Lãnh đạo doanh nghiệp hòa đồng và vui vẻ với mọi người & 274 & 3.11 \\
\hline $\begin{array}{l}\text { Doanh nghiệp này thường tham gia các hoạt động từ thiện như giúp đỡ người } \\
\text { khuyết tật, trẻ em, người nghèo v.v }\end{array}$ & 274 & 3.08 \\
\hline $\begin{array}{l}\text { Doanh nghiệp này có nhiều hoạt động tài trợ giúp nâng cao nhận thức trong cộng } \\
\text { đồng }\end{array}$ & 274 & 3.00 \\
\hline $\begin{array}{l}\text { Doanh nghiệp này có nhiều đóng góp vào các dự án cải thiện “chất lượng cuộc } \\
\text { sống” của cộng đồng. }\end{array}$ & 274 & 3.06 \\
\hline Doanh nghiệp này có nhiều chương trình tài trợ học bổng cho cộng đồng & 274 & 3.03 \\
\hline $\begin{array}{l}\text { Doanh nghiệp này có nhiều hoạt động trong việc nâng cao nhận thức và bảo vệ } \\
\text { môi trường }\end{array}$ & 274 & 3.33 \\
\hline Doanh nghiệp này có không gian môi trường làm việc xanh, sạch & 274 & 3.39 \\
\hline
\end{tabular}




\begin{tabular}{|l|l|l|}
\hline $\begin{array}{l}\text { Doanh nghiệp này có môi trường làm việc an toàn (trang bị các thiết bị chữa cháy, } \\
\text { lôi thoát hiêm, dụng cụ bảo hộ lao động v.v) }\end{array}$ & 274 & 3.32 \\
\hline Doanh nghiệp này có môi trườn làm việc thân thiện với khách hàng & 274 & 3.18 \\
\hline $\begin{array}{l}\text { Anh chị sẽ không mua sản phẩm hoặc dịch vụ của một DN từ chối tham gia vào } \\
\text { hoạt động trách nhiệm xã hội }\end{array}$ & 274 & 3.18 \\
\hline $\begin{array}{l}\text { Anh chị sẽ chi trả nhiều tiền hơn để mua những sản phẩm hoặc dịch vụ thực hiện } \\
\text { tốt hoạt động trách nhiệm xã hội }\end{array}$ & 274 & 3.30 \\
\hline $\begin{array}{l}\text { Nếu giá và chất lượng địch vụ của hai sản phẩm giống nhau. Anh chị sẽ mua } \\
\text { những sản phẩm và dịch vụ của DN nổi tiếng về thực hiện trách nhiệm xã hội }\end{array}$ & 274 & 3.23 \\
\hline
\end{tabular}

Kết quả kiểm định trung bình của các thang đo cho thấy rằng, hầu hết các thang đo đều có giá trị trung bình khá từ 3.03 đến 3.57. Thang đo "Trách nhiệm về kinh tế", các biến quan sát dao động từ 3.33 đến 3.48 và thang đo "Trách nhiệm về pháp luật", các biến quan sát dao động từ 3.13 đến 3.57. Thang đo "Trách nhiệm về đạo đức" là khá thấp so với các thang đo còn lại, các biến quan sát dao động từ 3.04 đến 3.18. Như vậy, khách hàng chưa thật sự đánh giá cao về thái độ, trách nhiệm về đạo đức của các doanh nghiệp, đây là một trong những yếu tố cần được cải thiện để nâng cao uy tín thương hiệu cho doanh nghiệp TPHCM.

\section{2. Đánh giá độ tin cậy của thang đo và giá trị hội tụ của nhóm nhân tố}

Bảng 3. Kiểm định mức độ tin cậy của thang đo - Cronbach's Alpha

\begin{tabular}{|l|l|l|l|}
\hline BIẾN & Mã hóa & Nhân tố & Hệ số Cronbach's Alpha \\
\hline \multirow{3}{*}{ Biến độc lập } & KT & Trách nhiệm về kinh tế & 0,810 \\
\cline { 2 - 4 } & PL & Trách nhiệm về pháp luật & 0,864 \\
\cline { 2 - 4 } & DD & Trách nhiệm về đạo đức & 0,812 \\
\cline { 2 - 4 } & TT & Trách nhiệm về từ thiện & 0,758 \\
\cline { 2 - 4 } & MT & Trách nhiệm về môi trường & 0,842 \\
\hline Biến phụ thuộc & HVM & Đánh giá chung & 0,874 \\
\hline
\end{tabular}

Kết quả kiểm định thang đo cho thấy thang đo có độ chính xác khá cao với hệ số Cronbach's Alpha > 0,7 và các hệ số tương quan biến tổng của các biến đo lường yếu tố này đều đạt chuẩn cho phép $(>0,3)$, các thang đo đều được chấp nhận. Từ đây tiến hành phân tích nhân tố khám phá ở bước tiếp theo.

\begin{tabular}{|c|c|c|c|c|c|c|}
\hline & & & & & & \\
\hline Các khái niệm & Ký hiệu & & & hân t & & \\
\hline & & 1 & 2 & 3 & 4 & 5 \\
\hline & DD4 & .801 & & & & \\
\hline & DD5 & .795 & & & & \\
\hline Trách nhiệm xã & DD2 & .769 & & & & \\
\hline hội về đạo đức & DD3 & .759 & & & & \\
\hline & DD6 & .741 & & & & \\
\hline & DD1 & .658 & & & & \\
\hline & MT4 & & .828 & & & \\
\hline Trách nhiệm xã & MT2 & & .824 & & & \\
\hline hội về môi trường & MT1 & & .792 & & & \\
\hline & MT3 & & .689 & & & \\
\hline & TT2 & & & .827 & & \\
\hline Trách nhiệm xã & TT3 & & & .742 & & \\
\hline hội về từ thiện & TT1 & & & .740 & & \\
\hline & TT4 & & & .725 & & \\
\hline & KT3 & & & & .786 & \\
\hline Trách nhiệm xã & KT4 & & & & .751 & \\
\hline hội về kinh tế & KT2 & & & & .741 & \\
\hline & KT1 & & & & .786 & \\
\hline
\end{tabular}




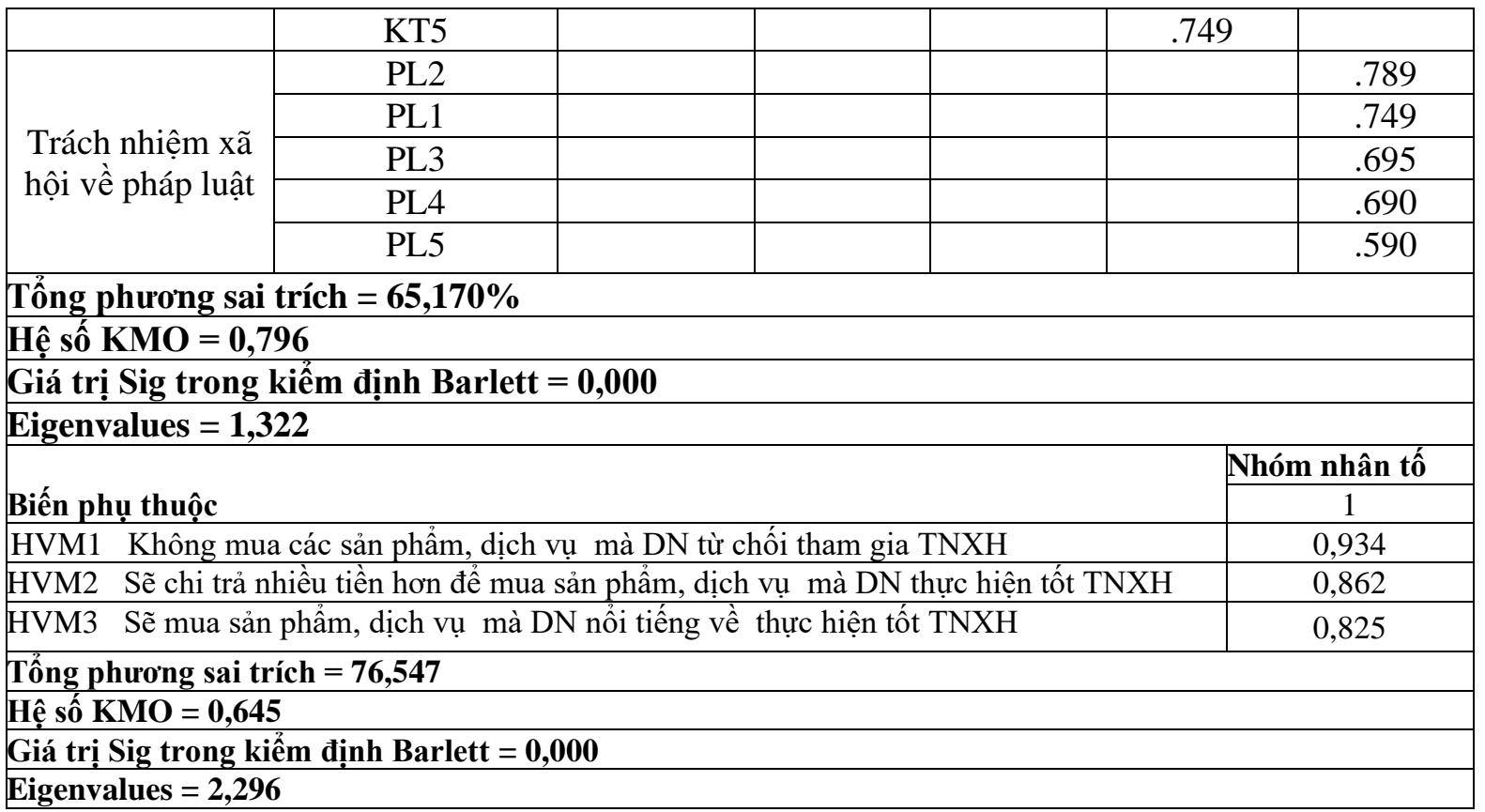

Qua kết quả kiểm định phân tích nhân tố trong bảng 4 cho thấy các chỉ số trong phân tích EFA đã thỏa các điều kiện sau: Giá trị KMO của nhóm biến độc lập là 0,796 và nhóm biến phụ thuộc là 0,645 (điều kiện: lớn 0.5 và nhỏ hơn 1) từ đó cho thấy phân tích nhân tố là phù hợp. Giá trị Sig của Bartlett's của cả nhóm biến độc lập và phụ thuộc đều bằng 0 nhỏ hơn mức ý nghĩa alpha $5 \%$ cho thấy các biến quan sát có tương quan với nhau trong tổng thể. Hệ số Eigenvalue của nhóm biến độc lập là 1,322 và nhóm biến phụ thuộc là 2,236 đều lớn hơn 1 , thì nhân tố rút trích được có ý nghĩa tóm tắt thông tin tốt. Tổng phương sai trích bằng của nhóm biến độc lập là 65,170 và nhóm biến phụ thuộc là 76,547 (>50\%), điều này cho thấy 5 nhân tố độc lập rút trích được giải thích $65,170 \%$ biến thiên của dữ liệu quan sát và 1 nhân tố phụ thuộc rút trích được giải thích $76,547 \%$ biến thiên của dữ liệu quan sát. Kết luận là dữ liệu có ý nghĩa để thực hiện các phân tích tiếp theo.

\subsection{Phân tích tương quan và phương trình hồi quy}

Xem xét các mối quan hệ tương quan giữa biến phụ thuộc với từng biến độc lập thông qua phân tích tương quan Pearson. Nếu hệ số tương quan giữa biến phụ thuộc và biến độc lập lớn chứng tỏ giữa chúng có mối quan hệ với nhau, và phân tích hồi quy là phù hợp. Ngược lại, nếu các biến độc lập cũng có hệ số tương quan với nhau lớn thì có thể xảy ra hiện tượng đa cộng tuyến trong mô hình hồi quy đang xem xét.

Bảng 5. Kết quả ý nghĩa mô hình dự báo sau khi phân tích hồi qui

\begin{tabular}{|c|c|c|c|c|c|c|c|c|}
\hline \multirow{2}{*}{\multicolumn{2}{|c|}{ Mô hình }} & \multicolumn{2}{|c|}{$\begin{array}{c}\text { Hệ số chưa chuẩn } \\
\text { hóa }\end{array}$} & \multirow{2}{*}{$\begin{array}{c}\begin{array}{c}\text { Hệ số } \\
\text { chuẩn hóa }\end{array} \\
\text { Beta } \\
\end{array}$} & \multirow[t]{2}{*}{$\mathbf{t}$} & \multirow[t]{2}{*}{ Sig. } & \multicolumn{2}{|c|}{ Đa cộng tuyến } \\
\hline & & B & $\begin{array}{l}\text { Std. } \\
\text { Error }\end{array}$ & & & & \multirow[t]{2}{*}{$\begin{array}{c}\text { Toleran } \\
\text { ce }\end{array}$} & \multirow[t]{2}{*}{ VIF } \\
\hline 1 & (Constant) & .2979 & .487 & & 6.120 & .000 & & \\
\hline & $\mathrm{KT}$ & .630 & .074 & .199 & 8.536 & .000 & .893 & 1.120 \\
\hline & PL & .380 & .081 & .260 & 4.668 & .000 & .847 & 1.181 \\
\hline & $\mathrm{DD}$ & .425 & .094 & .265 & 4.502 & .000 & .848 & 1.180 \\
\hline & TT & .264 & .070 & .176 & 3.762 & .000 & .831 & 1.203 \\
\hline & MT & .176 & .085 & .108 & 2.063 & .040 & .948 & 1.055 \\
\hline
\end{tabular}

Biến phụ thuộc: HVM

$\mathbf{R}^{2}=\mathbf{5 9 , 9}$ 
Sig $=0,000$

\section{Durbin - Watson $=\mathbf{2 , 0 9 6}$}

Theo kết quả bảng 5 cho thấy đo lường đa cộng tuyến: Hệ số phóng đại phương sai VIF của các biến là nhỏ (lớn nhất là $\mathrm{VIF}=1.203<2$ ). Do đó, hiện tượng đa cộng tuyến giữa các biến độc lập trong mô hình này là nhỏ, không có ảnh hưởng đáng kể đến kết quả hồi qui.Tham số $\mathrm{R}$ bình phương hiệu chỉnh (Adjusted $\mathrm{R}$ Square) cho biết mức độ (\%) sự biến thiên của biến phụ thuộc được giải thích bởi biến độc lập.

Nhìn vào bảng 5 , kết quả hồi qui cho thấy $59,9 \%$ của mô hình 1 có ý nghĩa là sự biến thiên của HVM được giải thích bằng sự biến đổi của 5 nhân tố (KT, PL, DD, TT, MT) còn lại 40,1\% được giải thích bởi các yếu tố khác. Giá trị Durbin-Watson bằng 2,096, thuộc khoảng $(1,3)$ do đó mô hình hồi quy không bị đa cộng tuyến. Qua bảng phân tích phương sai ANOVA cho thấy trị số $\mathrm{F}=50.159$ và có mức ý nghĩa sig. $=0,000$ (sig. $\leq 0.05$ ), có ý nghĩa mô hình hồi quy phù hợp với dữ liệu thu thập được và các biến đưa vào đều có ý nghĩa trong thống kê với mức ý nghĩa $5 \%$. Nhìn vào hệ số Beta cho thấy mức ảnh hưởng của 5 biến độc lập tới biến phụ thuộc và tầm quan trọng của từng biến độc lập trong mô hình lần lượt như sau: $\mathrm{KT}=0,199$; $\mathrm{PL}=0,265 ; \mathrm{DD}=0,260 ; \mathrm{TT}=0,176 ; \mathrm{MT}=0,108$; Từ kết quả phân tích ta có mô hình hồi qui: $\mathrm{HVM}=$ $0.265 * \mathrm{PL}+0.260 * \mathrm{DD}+0.199 * \mathrm{KT}+0.176 * \mathrm{TT}+0.108 * \mathrm{MT}$

\section{KẾT LUẬn VÀ HÀM Ý QUẢN TRI}

\subsection{Kết luận}

Kết quả kiểm định mô hình cho thấy sự tác động trách nhiệm xã hội của DN đến hành vi mua của khách hàng tại $\mathrm{TPHCM}$ và mức độ ảnh hưởng của từng nhân tố là khác nhau. Kết quả nghiên cứu này thực hiện được các mục tiêu như sau: Thứ nhất, xác định được các nhân tố tác động đến hành vi mua của khách hàng tại TPHCM; Thứ hai, xác định được thứ tự ưu tiên mức độ tác động các nhân tố đến hành vi mua của khách hàng tại TPHCM; Thứ ba, đề xuất các giải pháp nhằm giúp các nhà quản trị doanh nghiệp hoạch định chiến lược, phát triển bền vững, nâng cao uy tín thương hiệu, gia tăng khả năng cạnh tranh của các doanh nghiệp kinh doanh tại TPHCM trong xu thế cạnh tranh hội nhập hiện nay.

\subsection{Hàm ý quản trị}

Từ kết quả nghiên cứu có 5 thành phần TNXH ảnh hưởng đến hành vi mua của khách hàng. Bất kỳ một sự thay đổi nhận thức nào về 5 thành phần trên cũng ảnh hưởng đến hành vi mua của khách hàng. Do đó để giữ chân khách hàng và thu hút khách hàng mới, các doanh nghiệp nên tập trung vào các thành phần của TNXH theo thứ tự mức độ ưu tiên như sau: pháp luật, đạo đức, kinh tế, từ thiện và môi trường, đặt biệt nên quan tâm đến nhóm khách hàng có độ tuổi dưới 60 tuổi với mức thu nhập trung bình từ 5 triệu đồng đến 15 triệu đồng trở lên. Một số kiến nghị sau:

Trách nhiệm pháp lý được khách hàng nhận thức là yếu tố quan trọng nhất, sau đó là trách nhiệm đạo đức, kinh tế, từ thiện và môi trường. Điều này có thể lý giải do Việt Nam vẫn còn chưa phải là một quốc gia phát triển, còn nhiều cơ sở sản xuất, kinh doanh chưa tuân thủ pháp luật và thiếu đạo đức kinh doanh, dẫn đến thiệt hại cho khách hàng và xã hội. Do đó yêu cầu của TNXH DN tại Việt Nam còn ở mức tối thiểu là tuân thủ luật pháp, có đạo đức trong kinh doanh, kinh doanh có hiệu quả và quan tâm đến công đồng và môi trường sống xunh quanh.

Kết quả này còn cho thấy doanh nghiệp nên rà soát lại các yếu tố đầu vào và đầu ra trong quá trình sản xuất để cải thiện quy trình sản xuất. Từ đó doanh nghiệp có chính sách giảm giá thành sản phẩm, giá bán hợp lý và thường xuyên có kế hoạch đánh giá lại điểm mạnh, điểm yếu của mình từ đó xác định vị thế cạnh tranh của doanh nghiệp trên thị trường.

Ngoài ra doanh nghiệp nên triển khai sâu rộng các chương trình từ thiện đến mọi tầng lớp nhân dân để họ thẩu hiểu lợi ích của chương trình mang lại cho cộng đồng. Từ đó khách hàng quan tâm nhiều hơn và chung tay góp sức với doanh nghiệp; Thành lập quỹ hổ trợ cộng đồng, đây là quỹ chính thức được ban lãnh đạo doanh nghiệp cam kết duy trì. Quỹ hổ trợ này trích ra từ nguồn lợi nhuận sau thuế của doanh nghiệp; Xây dựng các đề án bảo vệ môi trường và tích cực tham gia vào các chương trình bảo vệ môi trường, đồng thời bản thân doanh nghiệp phải là đơn vị đi đầu trong việc giảm thiểu chất thải nguy hại thải ra môi trường xunh quanh.

Ngày nay, doanh nghiệp phải chú trọng đến đạo đức trong kinh doanh và xem đạo đức trong kinh doanh là chìa khóa thành công của doanh nghiệp. Vì vậy để duy trì và thực hiện tốt điều này nên xây dựng một bộ 
quy tắc ứng xử có đạo dức của doanh nghiệp và $\mathrm{DN}$ phải tôn trọng và tuân thủ các chuẩn mực đạo đức mà xã hội công nhận.

\section{HẠN CHẾ CỦA NGHIÊN CÚU}

Nghiên cứu này chỉ thực hiện tại khu vực Thành phố Hồ Chí Minh với phương pháp chọn mẫu thuận tiện theo đủ số mẫu để phân tich cho mô hình tổng quát. Khả năng tổng quát hóa sẽ cao hơn nếu nó được lập lại tại một tỉnh thành phố khác tại Việt Nam với một phương pháp chọn mẫu có tính đại diện cao hơn. Vì vậy hướng nghiên cứu tiếp theo là hướng nghiên cứu lặp lại tại một tỉnh thành phố lớn ở Việt Nam với phương pháp chọn mẫu ngẫu nhiên.

\section{TÀI LIỆU THAM KHẢO}

[1] Carroll, A. B., 1991. The pyramid of corporate social responsibility: Toward the moral management of organizational stakeholders. Business horizons. 34/4: 39-48.

[2] Hà .N.T.H, Mai. N.T.T (2013), Trách nhiệm xã hội doanh nghiệp và cảm nhận của khách hàng- Nghiên cứu định tính trong ngành Thức ăn chăn nuôi tại miền Bắc, Tạp chí Kinh tế phát triển, số 195.

[2] Nhã P. T. N. và Xuân T. T. L. (2014), Nhận thức của người tiêu dùng về trách nhiệm xã hội của doanh nghiệp và ý định mua - một nghiên cứu từ ngành hàng điện máy, Tạp chí khoa học Đại học Mở Thành phố Hồ Chí Minh, 3 (36), 60-77.

[4] Ánh N.T.K, Hòa N.T.H (2018), Ảnh hưởng của cảm nhận trách nhiệm xã hội đến niềm tin thương hiệu - trường hợp dịch vụ vận tải khách thương hiệu phúc thuận thảo, Tạp chí Khoa học Đại học Huế: Kinh tế và Phát triển, Tập 127, Số 5A, 53-71

[5] Chester Barnard (1938), The Functions of the Executive. Harvard University Press, 1938

[6] J. M. Clark’s (1933) Social Control of Business, University of Chicago Press, 1933

[7] Theodore Kreps's (1940). Measurement of the Social Performance of Business. U.S. Government Printing Office.

[8] H.R. Bowen. Social Responsibilities of the Businessman, Oxford University Press \& New York, 1953

[9] Lois a. Mohr; Deborah j. Webb; Katherine e. Harris (2001), Do consumers expect companies to be socially responsible? the impact of corporate social responsibility on buying behavior. Journal of consumer affairs 35(1):4572

[10] Ogrizek, M.(2002). The effect of corporate social responsibility on the branding of financial services. Journal of Financial Services Marketing. 1 (6): 215-228.

[8]Dahlsrud 2008, How corporate social responsibility is defined: an analysis of 37 definitions, Corporate Social Responsibility and Environmental Management, 15, (1-13)

[9] Zenisek, 1979, Corporate Social Responsibility: A Conceptualization Based On Organizational Literature, The Academy of Management Review, 4(3)

[10] Brown, T.J. and Dacin, P.A. (1997) The Company and the Product: Corporate Associations and Consumer Product Responses. Journal of Marketing, 61, 68-84.

[11] Malik, M., 2015. Value - Enhancing Capabilities of CSR: A Brief Review of Contemporary Literature. Journal of Business Ethics. 127: 419-438.

[12] Becker-Olsen, K. L., Cudmore, B. A., Hill, R. P., 2006. The impact of perceived corporate social responsibility on consumer behavior. Journal of Business Research. 59/1: 46-53

[13] Lee, Y. K., Lee, K. H., and Li, D. X., 2012. The impact of CSR on relationship quality and relationship outcomes: A perspective of service employees. International Journal of Hospitality Management. 31/3: 745-756.

[14] Pérez, A., and del Bosque, I. R., 2014. Customer CSR expectations in the banking industry. International Journal of Bank Marketing. 32/3: 223-244.

[15] Pérez, A., and del Bosque, I. R., 2015. Customer values and CSR image in the banking industry. Journal of Financial Services Marketing. 20/1: 46-61.

[16] Fatma, M., and Rahman, Z., 2016. The CSR's influence on customer responses in Indian banking sector. Journal of Retailing and Consumer Services. 29: 49-57.

[17] MORI, 2000. SMEs' Attitudes to Social Responsibility (Impact onSocietyTaskforce). London.

[18] Carvalho, S. W., Sen, S., de Oliveira Mota, M., \& de Lima, R. C., 2010. Consumer reactions to CSR: A Brazilian perspective. Journal of Business Ethics. 91: 291-310. Clarkson, M. E., 1995. A stakeholder framework for analyzing and evaluating corporate social performance. Academy of management review. 20/1: 92-117.

[19] Polychronidou, P., Ioannidou, E., Kipouros, A., Tsourgiannis, L., \& Simet, G. F., 2014. Corporate Social Responsibility in Greek Banking Sector-An Empirical Research. Procedia Economics and Finance. 9: 193-199

[20] Lê Thanh Hà, 2006, Trách nhiệm xã hội trong vấn đề tiền lương, báo lao động xã hội, số 290 ngày 15/05/2006

[21] Duoong Công Danh (2015), Nhận thức của nguời tiêu dùng về trách nhiệm xã hội của doanh nghiệp, Tạp chí Kinh tế phát triển, số 2017, trang 24-32; 


\section{TÁC ĐộNG TRÁCH NHIỆM XÃ HộI CỦA DOANH NGHIỆP ĐẾN HÀNH VI MUA CỦA KHÁCH HÀNG TẠI THÀNH PHỐ HỒ CHÍ MINH}

[22]. Nhã P. T. N. và Xuân T. T. L. (2014), Nhận thức của người tiêu dùng về trách nhiệm xã hội của doanh nghiệp và ý định mua - một nghiên cứu từ ngành hàng điện máy, Tạp chí khoa học Đại học Mở Thành phố Hồ Chí Minh, 3 (36), 60-77.

[23] Pomering, A., and Dolnicar, S., 2009. Assessing the prerequisite of successful CSR implementation: are consumers aware of CSR initiatives? Journal of Business Ethics. 85/2: 285-301.

[24] Environics. (1999). The millennium poll on corporate social responsibility.

Retrieved from http://www.mori.com.

[25] Tay K. L. (2005c). CSR and consumers. Business \& Accounting Accountant Today. Pp. 24-27

[26] Rahim. R.A, Jalaludin.W.F and Kasmah Tajuddin (2011). The importance of corporate social responsibility on consumer behaviour in Malaysia. Asian Academy of Management Journal, Vol. 16, No. 1, 119-139

[27] Philip Kotler. Principles of Marketing. Prentice Hall, 2010

[28] Trọng H. \& Ngọc C. N. M. (2008), Phân tích dữ liệu với SPSS, Tập 2, Nxb. Hồng Đức, TP. HCM.

[29] Hair \& ctg (1998), Multivariate Data Analysis, Prentice-Hall International.

Ngày nhận bài: 08/12/2018

Ngày chấp nhận đăng : 20/03/2019 